\title{
Inconsistency in Information Resources of Modern Education
}

\author{
https://doi.org/10.3991/ijet.v17i03.25763 \\ Dmitry V. Rakhinsky ${ }^{1,2,3(\bowtie)}$, Mikhail P. Yatsenko ${ }^{1}$, Irina G. Sinkovskaya ${ }^{4,1}$, \\ Svetlana P. Shtumpf 5 \\ ${ }^{1}$ Siberian Federal University, Krasnoyarsk, Russia \\ ${ }^{2}$ V.F. Voino-Yasenetsky Krasnoyarsk State Medical University, Krasnoyarsk, Russia \\ ${ }^{3}$ Krasnoyarsk State Agrarian University, Krasnoyarsk, Russia \\ ${ }^{4}$ Reshetnev Siberian State University of Science and Technology, Krasnogorsk, Russia \\ ${ }^{5}$ Krasnoyarsk State Pedagogical University named after V.P. Astafiev, Krasnoyarsk, Russia \\ drakhinsky@sfu-kras.ru
}

\begin{abstract}
The article investigates the problem of the ambiguous influence of modern information technologies on education. The authors analyse not only the positive effects of computerisation. They also identify the problems faced by the subjects of the educational process under the influence of digitalisation. As outlined in the article, uncontrolled information flows prevent students from forming the holistic worldview. The dominance of information technologies in education also leads to the transformation of subject-object relations in the process of cognition. The teacher, whose role is changed significantly, acts more frequently as a coordinator. The usage of gadgets in the educational process provides an opportunity to receive an education at a distance. However, the widespread use of distance learning technologies leads to a decline in the quality of educational services. This resulted from the need to develop new methods. In addition, the constant updating of information technologies does not allow the teacher to develop a sustainable methodology for teaching their subject. The authors prove that the active use of digital technologies in the information society implies the harmonious combination of traditional and modern information technologies. This fully applies to the modern Russian education system, which is in an intermediate state between traditional pedagogical methods and modern computer technologies. As the authors point out, the problem is to find the optimal educational option for the formation of a harmonious global-regional educational system. It should not only include all the advantages of the latest information technologies, but also preserve all the positive achievements of great practitioner-teachers and scientists.
\end{abstract}

Keywords-modern information technologies, education system, educational process, digitalisation, information resources, computerisation 


\section{Introduction}

The latest information technologies have created conditions for significant transformations in all social institutions, which is most evident in the educational system. Many researchers regret that human beings are gradually becoming slaves to electronic technologies in recent years, actively using gadgets in everyday life for quick access to any kind of information, as well as for constant communication with their friends, relatives, colleagues anywhere in the world. It is safe to say that at present, modern electronic technologies have firmly entered the field of education, regardless of gender, age, nationality, as well as the economic situation of students [1].

The use of information technologies in the educational process is primarily aimed at obtaining operational information, although this often leads to a decrease in the quality of the information received. In the process of its accumulation, such information appears, the meaning of which cannot be restored at all because more often "there is an increase in the imbalance of semantic and informational components in society, with the predominance of information" [2]. The main problem faced by the participants of the educational process, who are cultivating information resources as the dominant ones, is that the student completely relying on technology gradually turns in such conditions into an object of manipulation which does not have the signs of independence. If such a young person represents a personality with a not fully formed worldview, then there is a threat of losing the qualities which are necessary for the emergence of a generation of worthy citizens. They obtain knowledge from chaotic information flows, where, as a rule, there is no certain axiological scale, because these information resources, as J. Gomez-Galan rightly emphasizes, are obtained by such a young man from social networks and other public Internet communication channels. In addition, according to the reasonable remark of the abovementioned author, any acquired knowledge is overlaid with cultural universals and everyday customs, which lead to the emergence of common interests and have a noticeable impact, including on the educational space [3].

The digitalisation of the educational sphere demonstrates that the universalisation of social space, manifested in the form of globalisation, is largely due to technological determination, which transforms the entire system of social communications significantly. Certainly, changes in the educational system largely determine the vector of the entire social process, that is, the culture of the information society is formed [4]. The undeniable advantages of digitalization include the following:

1. expanding the boundaries of "independent learning";

2. differentiation of training forms and methods;

3. creating conditions for the formation of individual educational trajectories of students;

4. leadership development in the teaching environment;

5. modernisation of student knowledge assessment tools [5].

However, these processes are not so unambiguous, and the consequences of the spontaneous introduction of computer technologies are not sufficiently calculated by 
specialists in the field of pedagogy and psychology, so the impact of digitalisation on individual stages of education and upbringing requires a separate in-depth analysis.

The inconsistency of information flows creates a dangerous illusion of the constant updating of an education institution as a social institution. Thus, the important function of education, which acts not only as a leading guardian of social traditions, but also as a translator of the best ones, is violated. The situation is similar in cases where the specifics of developing production or individual social institutions are wrongfully transferred to the educational system. The innovative nature of information as its most important characteristic constantly forces teachers to develop new methodological techniques that can differ fundamentally in the system of natural and humanitarian knowledge. The concept of "advanced education", which emerged in the mid-90s of the 20th century, can serve as an example and is considered by some specialists in the field of pedagogy as a socio-philosophical problem of the correlation of old and new social institutions, which is not always confirmed in practice [6].

\section{$2 \quad$ Materials and methods}

The digitalisation of the educational sphere demonstrates that the universalisation of social space, manifested in the form of globalisation, is largely due to technological determination, which transforms the entire system of social communications significantly. Certainly, changes in the educational system largely determine the vector of the entire social process, that is, the culture of the information society is formed [4]. That is why the impact of digitalisation on individual stages of education and upbringing requires a separate in-depth analysis as the consequences of the spontaneous introduction of computer technologies are not sufficiently calculated by specialists in the field of pedagogy and psychology. The specifics of forming an effective digital space in the humanitarian educational sphere is that it should be based on the leading traditions of a particular society, determined by legal or moral norms. The established dominance of the latest digital technologies changes the very essence of relationships among the subjects of the educational process, and not only changes the methodology of cognition in the process of mastering specific academic disciplines. The use of the semi-formalised interview method in the framework of intelligence research (from April to June 2021) aimed at evaluating the effectiveness of the use of digital technologies in the educational process by university teachers and senior students, revealed contradictions in the practices of using them in the educational process. In the research process, 25 teachers and 130 full-time students studying Bachelor degree programmes from different institutes of the Siberian Federal University (Krasnoyarsk, Krasnoyarsk Region, Russia) were randomly selected and interviewed. The main objectives of the study were: to determine the frequency of use of digital technologies in the educational process; to identify an assessment of the ease of technical use of digital technologies; to identify an assessment of the effectiveness of communication tools (forums, chats, announcements); to identify an assessment of training content (tests, exercises, training materials), to identify an assessment of data management 
(statistics, monitoring, portfolio, etc.); to identify the advantages and disadvantages of digital technologies in the educational process of the university.

\section{Discussion}

An important issue caused by the accelerated introduction of information technologies in the educational process is related to the fact that educational information is perceived by modern students by analogy with the pre-computer era as primary information. Research shows that the modern information revolution is characterised in the field of education by the formation of an information worldview, which not only creates a new educational space, but also significantly changes the traditional material-energy world-view, the scientific paradigm and the methodology of scientific research [7]. In contrast to the socio-cultural personality, which is subject to changes on the part of society, in global education, anthropocentric attitudes are leading, presenting a "free personality" through the cultivation of the "human factor". This approach often leads to the fact that the goal of a certain group of participants in the educational process is to release information in the network community, which is able to provoke a break in communication within a particular social group. The educational space, which is expanding through new information technologies, puts forward new standards in the communication of all participants in the educational process. This is due to the fact that the traditional education system was based on the thesis of the leading subjects in the educational process, where the world around acted as an auxiliary. In the information society, information culture is of crucial importance. The education system has a special role in its formation, since it is education that is the core of the future information society [8].

Many scientists point to the key risks of online learning, in which, according to E.V. Frolova, direct communication channels are missing, but also the practice of imitating the educational activities of students in the context of a decrease in the control function of the teacher is spreading [9]. Further, this author points out the key limitations of the imposition of digital technologies and highlights the following among them: imperfection of the material and technical base; dysfunctions in the system of control and motivation of teachers; low level of moderation of educational content; lack of digital trust, etc [10].

This trend, which characterizes modernity quite clearly, is analyzed in detail in the article by S.G. Gorin, where he, in particular, notes, "The development and complexity of the organization of society, the transition from the industrial type of society to the informational one, to new technological structures determines the non-linearity of its development, expressed in contradictory social processes that have a cyclical, wave character"[11].

The actualisation of the theory of value-oriented knowledge, which affects the goals and methods of various forms of education, implies a certain degree of operationality, since this cognitive mechanism determines the resolution of issues related to the social organization of society. The growing problem of "dehumanisation" in the conditions of a sharply expanded educational space is manifested in many directions, 
but this process can be observed as much as possible in modern education. "Foreign models of education are sometimes blindly introduced into the educational process: we observe the active introduction of the Western system of values and life attitudes into the Russian reality" [12].

These trends in the educational space have their own specifics because the educational space in each country is formed taking into account the goals that this society pursues to preserve its identity. The younger generation is determined to create their own communication communities, networks developing communication strategies at all levels of socialisation. According to I.V. Yakovleva, "the challenges of the time force people to rethink the role of the education system in the processes of industrial reconstruction and transition to the sixth technological order, which requires a new new insight into the tasks of building a "digital" economy and the specifics of training modern labour resources, including engineering and humanitarian personnel. The most popular professions in the near future will be in the sphere of high technology, among them - the industry of big numbers and their processing, artificial intelligence... In the future, the greatest results should be expected from those who work at the interface between different sciences, as the boundaries between branches of knowledge are blurred" [13]. The current situation resulted from the fact that the network community sets a certain vector for the entire educational process as any epistemological acts include various communication strategies. Various manipulative practices, often including negative information, occupy an important place in the educational space, since such resources are created in different formats without taking into account the specifics of the educational process, as well as the needs of users. The provision of such information resources leads to a decrease in the quality of the educational process. Such negative trends are determined by the lack of clear principles for the presentation of educational material, as well as technologies for the accumulation of relevant information and effective methods of conducting the educational process. "The student should ideally learn "for himself", meaning his own formation and development for further productive activities. And so the goals of selfdevelopment (what, in fact, is worth studying for) are postponed to an uncertain future, while the other goals concerning the formal side of education are moving to the foreground" [14].

\section{$4 \quad$ Results}

Amount of knowledge, skills and abilities that a particular educational system provides are determined by social needs, where the need of young people for continuing education occupies an important place. Education also carries out an important mission related to the accumulation of life experience and the ability to solve not only personal, but also social problems. In this regard, one can hardly overestimate the role of education in promoting the social and creative self-realisation of students by encouraging them to lead a healthy lifestyle [15]. The fact is that this pedagogical concept going back to the ideas of great thinkers is connected with religious ideas about the spiritual improvement of a person. Despite the fact that the leading pedagogical 
ideas are of universal character, they always have a specific character, which is imposed by the history, traditions and mentality of a particular society. Recently, there has been a deformation of the leading pedagogical principles at all levels, which is due to global trends. That is why the creation of information technologies that will be designed for the development of digital educational processes, i.e. gadgets designed to stimulate the cognitive interest of the younger generation, has recently become very popular [16]. At the same time, it is difficult not to agree with the opinion of V.I. Kudashov who proves that any integral image should cover the entire path in its historical and informational plan without distinguishing its temporal constructs for the past, present and future [17].

At the present stage of development, humanity is striving to attain a goal that is relevant for any historical period and is fully manifested in the educational system. The main danger for the younger generations is that modern media, which include all the media in the modern world, form a consumer type of personality, which provokes potential unreliability or even distortion of real facts, destroying moral and cultural forms of behaviour. An effective digital space would be possible if humanities education became equivalent to natural and technical education, since not only being determines consciousness, but also consciousness determines being. At the same time, the quality of consciousness depends on the quality of the human sciences and education in the humanities that form it. This dialectical relationship is repeatedly confirmed by the facts and events of Russian reality. This aspect is of great importance for the Russian educational system, which has undergone serious transformations as a result of a radical change in the socio-cultural paradigm [18].

Enhancing the benefits of each society and its education system in a world, which is susceptible to universalist tendencies, contributes to the fight against "dehumanisation" manifested at all levels of any social system. However, alongside these trends, the need to use the latest information technologies in the context of a rapidly changing social structure is sharply increasing as they not only form a modern educational basis, but also facilitate the prediction of such social changes, as well as the development of effective feedback, etc.

Education largely sets the image of a high-tech future, which forms in the minds of young people new ideas about both the world around them and the person himself, who accumulates conscious and unconscious goals, as well as new knowledge, new values and norms. Modern technologies have a significant impact on the sociocultural environment of the person himself, directly affecting his biosocial essence and spiritual foundations, with the result that the person becomes the object of manipulation [19]. The manifestation of such tendencies appears to be particularly dangerous for the participants of the educational process, owing to their ideological instability, as well as nihilistic manifestations inherent in the representatives of the younger generation.

The ambiguity of the impact of information technologies on education and its participants is also manifested in the fact that the education system is directed to the future as it prepares potential specialists for a new, yet unknown reality. The need to adapt to this still little-known information reality significantly complicates the selfrealisation of modern young people, who, as a rule, do not yet have a stable 
worldview basis. Such trends lead to the disruption of traditional relations in education and lead to new social transformations. The way out of this situation, as reasonably considered by Navarro-Ibbarra, is to create training courses that include measures to develop a culture of proper use of Internet resources and reduce Internet addiction [20].

Virtual reality, which is an artificially constructed world, is gradually becoming more than just an imitation of real life, although this opinion was widespread several decades ago. This important, though relatively unknown facet of the very essence of life, being similar to the subconscious, provides new perspectives for self-affirmation in life, but in practice, unfortunately, the person plunged into virtual life, as a rule, turns into an element of the standard mass consciousness. The hopes that virtual reality can create special opportunities for students in terms of innovation are not justified. This is due to the fact that the innovative vector in the educational sphere is often specially designed as a pedagogical initiative. The ambivalence of the processes observed in modern Russian education is due to information technologies to the extent that teachers are able to use the new digital potential in combination with traditional methods. That is why it is important to take into account that the pedagogical process can fully manifest itself only in the presence of feedback, although the reforms undertaken in the field of the organisation of the educational process in modern Russia are mainly aimed at the maximum levelling of this important connection or at its complete destruction. In this regard, it is important to emphasise that we consider the development of education as a process that ensures the formation of a person capable of self-realisation in a contradictory changing world, which is guided by an established normative basis.

The ambivalence of the assessment of the use of digital technologies in the educational process was also evident in the results of the research conducted. The beginning of the Covid-19 pandemic hastened the use of new information technologies in the traditional system of full-time education, and since the beginning of March 2020, the university has completely switched to a distance learning format. Thus, both teachers and students have experience in using digital technologies in the educational process at the time of the study.

Before the imposition of the restrictive measures, $66 \%$ of teachers had experience working remotely on various digital platforms, but rated this as additional.

Table 1. Experience in working with digital technologies in the educational environment before the pandemic $(\%)$

\begin{tabular}{|l|c|c|c|c|}
\hline \multirow{2}{*}{ Response options } & \multicolumn{2}{c|}{ teachers } & \multicolumn{2}{c|}{ students } \\
\cline { 2 - 5 } & having experience & $\begin{array}{c}\text { lacking } \\
\text { experience }\end{array}$ & $\begin{array}{c}\text { having } \\
\text { experience }\end{array}$ & $\begin{array}{c}\text { lacking } \\
\text { experience }\end{array}$ \\
\hline 1. Third-party digital education platforms & 66 & 24 & 43 & 57 \\
\hline $\begin{array}{l}\text { 2. Virtual learning environment of the Uni- } \\
\text { versity (e-courses, webinars, etc.) }\end{array}$ & 60 & 40 & 53,4 & 46,6 \\
\hline $\begin{array}{l}\text { 3. Online conference platforms (ZOOM, } \\
\text { Skype, MS Teams, etc.) }\end{array}$ & 33 & 67 & 55,2 & 54,8 \\
\hline
\end{tabular}


The experience of working in the virtual learning environment of the University during the pandemic not only has enriched the practices of working on this platform, but also has formed the main opinions on the further application of distance education in the educational process (Table 2).

Table 2. Index analysis of respondents' assessing the judgments that characterise the prospects of the use of distance (digital) learning in the educational process of the university, on a scale: 0 - "I cannot answer", 1 - "I completely disagree", 2 - "I tend to disagree", 3 - "I tend to agree", 4 - "I fully agree"

\begin{tabular}{|l|l|l|}
\hline \multicolumn{1}{|c|}{ Judgements } & teachers & students \\
\hline $\begin{array}{l}\text { 1. Distance (digital) learning should become central to the educational process. } \\
\text { 2. Distance (digital) learning should be a necessary additional component of the } \\
\text { educational process. }\end{array}$ & 1,6 & 2,4 \\
\hline $\begin{array}{l}\text { 3. Distance (digital) learning can be used in both full-time and part-time modes of } \\
\text { study. }\end{array}$ & 2,8 & 3,8 \\
\hline $\begin{array}{l}\text { 4. The traditional instructional model cannot be replaced by the distance (digital) } \\
\text { instructional model. }\end{array}$ & 3,9 & 2.9 \\
\hline
\end{tabular}

Respondents generally describe it as a necessary, but alternative component of the educational system, which is kept up to date in situations of complicated access to the traditional education model (illness, business trips, work, pandemics, etc.). As the main technology of education, the digital learning model is considered only in relation to extramural and part-time (to a certain degree) forms of study.

Table 3. Index analysis of respondents' assessing the quality of conducting the educational process using distance (digital) learning in the Moodle system, on a scale: 0 - "I cannot answer", 1 - "very bad", 2 - "more likely to be bad", 3 - "more likely to be good", 4 "very good"

\begin{tabular}{|l|c|c|}
\hline \multicolumn{1}{|c|}{ Quality indicators } & teachers & students \\
\hline $\begin{array}{l}\text { 1. Technical usability (ease of use, speed of loading, modification, addition, updating } \\
\text { of educational materials) }\end{array}$ & 2,3 & 2,4 \\
\hline 2. "Feedback" communication tools (forums, chats, announcements) & 2,5 & 2,8 \\
\hline 3. Training content (tests, exercises, training materials) & 3,4 & 2,7 \\
\hline 4. Data management (statistics, monitoring, portfolio, etc.) & 2,5 & 2,4 \\
\hline $\begin{array}{l}\text { 5. Knowledge assessment (tests, examinations, pass-fail exams, term paper and } \\
\text { Bachelor's thesis defense, etc.) }\end{array}$ & 2,2 & 3,5 \\
\hline
\end{tabular}

The ease of technical use, which was understood by the respondents as the simplicity and speed of working with information materials (loading, changing, adding), was assessed by both sides of the educational process as "average", the main reason for this assessment was the difficulties associated with unformed user competencies. The same comments also applied to data management, which was assessed as "excessively overloaded with various actions". Particularly high number of negative comments was made about the statistics related to checking the student's tests, as well as the quality of "feedback". Teachers, in turn, noted the cases of system breakdowns deleting the 
status of the works which were already checked. All the students who were interviewed noted the lack of "live" communication with the teacher, especially when working with educational materials that were from their point of view related to materials of "increased complexity". The main ambivalence in the assessments was shown by the indicator of the training content. Students assessed the amount of material for academic disciplines as either insufficient or "excessive", unstructured, presenting difficulties of navigation, which, of course, reduced its value as an educational segment. Such results indicated the need to correct the list of questions for teachers. Besides, during the interview, a number of teachers were revealed to be disinterested in creating high-quality educational content due to a lack of confidence in preserving their copyrights to the material posted in the Moodle system, as well as awareness of the risks of losing their jobs due to the imposition and use of digital educational technologies.

The cluster analysis of the answers to the open questions related to the advantages and disadvantages of the digital instructional model revealed the following aspects.

Table 4. Positive and negative aspects of conducting the educational process using the distance (digital) learning model formulated by the respondents (\%)

\begin{tabular}{|l|c|c|}
\hline \multicolumn{1}{|c|}{ Positive aspects } & teachers & students \\
\hline $\begin{array}{l}\text { 1. Flexible schedule of the educational process (regardless of the time factor and } \\
\text { location) }\end{array}$ & 88 & 85,2 \\
\hline 2. Cost-effectiveness (should be cheaper than the traditional format) & 48 & 75,6 \\
\hline $\begin{array}{l}\text { 3. Accessibility (does not depend on distance, health status, the number of stu- } \\
\text { dents is not limited) }\end{array}$ & 100 & 63,6 \\
\hline \begin{tabular}{l|c|} 
4. Openness (availability of all training materials in the public domain) \\
\multicolumn{1}{|c|}{ Negative aspects }
\end{tabular} & 64 & 43 \\
\hline $\begin{array}{l}\text { 5. Not suitable for the programs of study where the main component is practice } \\
\text { or direct communication }\end{array}$ & 100 & students \\
\hline $\begin{array}{l}\text { 6. Increased workloads connected with completing, updating, and checking } \\
\text { training materials }\end{array}$ & 100 & 29,4 \\
\hline 7. Weak procedure for checking the authorship of completed tasks & 100 & 18 \\
\hline $\begin{array}{l}\text { 8. Limitations of the ability to control the degree of student involvement in the } \\
\text { educational process }\end{array}$ & 88 & 7.2 \\
\hline $\begin{array}{l}\text { 9. Weak legal and regulatory frameworks in the field of copyright regulation for } \\
\text { the content of educational courses }\end{array}$ & 100 & 0 \\
\hline 10. Monotonous presentation of the material & 80 & 3,6 \\
\hline 11. Harmful effect on the physical condition of the body & 700 & 81 \\
\hline 12. Decrease in students' skills related to "soft competencies" & 84 & 0 \\
\hline 13. Loss of the educational function aimed at students' identity development & 76,6 \\
\hline
\end{tabular}

The main advantages of the imposition of distance learning in the educational activities of the university, according to students, are: the availability of educational resources at any time, time saving due to the possibility of receiving education at home and on-the-job training; a variety of education forms. According to the teachers, the main advantage is the ability to engage in the educational process remotely, the 
disadvantages are the increased workloads associated with the need to download, check and update materials in the electronic system; weak legal and regulatory frameworks in the field of copyright regulation for the content of educational courses. One of the noted aspects of the imperfection of the digital educational system according to teachers is the separation of the educational function and the identity development function. The mediated nature of interaction in this educational technology minimises such significant components of the educational process as live communication between students and teachers that confirms axiological scales in the personal and professional spheres.

\section{Conclusion}

Modern world trends aimed at the universalisation of the world space imply a powerful information support, which is mainly manifested in regional educational systems that are unable to avoid negative global pressure. Educational systems can survive and continue to perform their main function only if they maintain their traditional axiological vector, which, in turn, is based on the historical past. It is clear that with all the positive consequences that global digitalisation brings, it is important to preserve the traditions, that seem as close as possible to national identity and national identity, in the education system. However, uncontrolled information flows lead to forming by the representatives of the younger generation a new axiological scale where the reviving interest in their culture is harmoniously combined with the values of the global world. It is therefore important in the context of the uncontrolled spread of the latest information technologies to develop an ability of schoolchildren to attempt to find a common platform on which not only coexistence, but also harmonious development is possible, instead of opposing the values of their society to other ethnic groups.

The revival of national education is only possible on the basis of the spiritual values, but modern pluralism is an external manifestation of diversity, which prevents the preservation of the socio-cultural identity of individual societies and specific individuals. It is known that unfounded pluralism is often embodied in school textbooks, which does not contribute to the formation of a holistic view of the world. The fact is that "in the information society, information culture, which is mainly formed by the education system that is the core of the future information society, becomes important" [8]. That is why "education using new information technologies should become the core of the information society and one of the priority mechanisms for further development..." [21-24].

Thus, education, which has lost the identity development functions, no longer serve as a basis for preserving the unity of Russia. The situation in modern Russia requires a redistribution of the roles of all participants in the educational process so that education could not only perform the required educational functions, but also solve the tasks of training a generation that is ready to live in the information society. 


\section{References}

[1] Kabanova, E.E. \& Vetrova, E.A. (2019). The Use of Modern Electronic Gadgets in the Educational Process of the University - European Journal of Contemporary Education, 8(3): 524-533. https://doi.org/10.13187/ejced.2019.3.524

[2] Vlaskin, A.V. (2014). The problem of loss of meaning and its impact on modern information communications. The fourth Siberian philosophical seminar "Modern philosophy in Russia: interdisciplinary research in the context of traditions and innovations", October 15-17, 2014, Omsk, pp. 164.

[3] Gómez-Galán, J., Martínez-López, J.A., Lázaro-Pérez, C. \& Fernández-Martínez M. (2021). Usage of Internet by University Students of Hispanic Countries: Analysis Aimed at Digital Literacy Processes in Higher Education - European Journal of Contemporary Education, 10(1): 53-65. https://doi.org/10.13187/ejced.2021.1.53

[4] Nizhegorodtsev, R.M. (2013). The formation of the information worldview and the tasks of the education field. Information and scientific worldview. Collection of scientific papers. Moscow: Russian school library association, pp. 432. http://sandbox.openclass.ru/ node/358509 (Accessed: 21.06.2019).

[5] Frolova, E.V., Rogach, O.V. \& Ryabova, T.M. (2020). Digitalization of Education in Modern Scientific Discourse: New Trends and Risks Analysis - European Journal of Contemporary Education, 9(2): 331-336. https://doi.org/10.13187/ejced.2020.2.313

[6] Novikov, P.N. \& Zuev, V.M. (1996). Advanced education: Hypotheses and realities. Moscow: Russian training center of the Federal employment service of Russia, pp. 136.

[7] Kolin, K.K. (2006). Informatics today and tomorrow: fundamental problems and prospects of development in the XXI century, Young people in the library business. Monthly professional magazine, 9-10 (September-October), pp. 16-26.

[8] Pfanenshtil, I.A., Yatsenko, M.P. \& Borisenko, I.G. (2014). Socio-philosophical aspects of the problems of engineering education in the context of information culture - Professional education in the modern world, 2(13): 80-86.

[9] Frolova, E.V., Rogach, O.V., Tyurikov, A.G. \& Razov P.V. (2021). Online Student Education in a Pandemic: New Challenges and Risks - European Journal of Contemporary Education, 10(1): 43-52. https://doi.org/10.13187/ejced.2021.1.43

[10] Frolova, E.V., Ryabova, T.M. \& Rogach O.V. (2019). Digital Technologies in Education: Problems and Prospects for "Moscow Electronic School" Project Implementation - European Journal of Contemporary Education, 8(4): 779-789. https://doi.org/10.13187/ejced.20 19.4.779

[11] Gorin, S.G. (2018). Intermediate results of educational transformations: a post-nonclassical approach - Professional education in the modern world, 8(1): 1624-1631.

[12] Chumakov, A.N. (2005). Globalisation. Contours of the integral world. Moscow: "Prospekt": TK Velbi, pp. 428.

[13] Yakovleva, I.V. (2019). Security of the Russian educational space: axiological content of the concept - Professional education in the modern world, 9(1): 2443-2450.

[14] Sevostyanov, D.A. (2019). Inversive analysis in modern education - Professional education in the modern world, 9(1): 2433-2442.

[15] Mutnikh, T.A. (2017). Features of the environment of the university in a small city, ensuring the development of general and professional competencies - Professional education in the modern world, 7(2): 1055-1057.

[16] Gruzina, Y.M., Ponomareva, M.A., Firsova, I.A. \& Mel'nichuk M.V. (2020). Present-Day Challenges to an Education System - European Journal of Contemporary Education, 9(4): 773-785. https://doi.org/10.13187/ejced.2020.4.773 
[17] Kudashov, V.I., Chernykh, S.I., Yatsenko, M.P., Grigoreva, L.I., Pfanenshtil, I.A. \& Rakhinsky D.V. (2017). Historical reflection in the educational process: an axiological approach - Analele Universitatii din Craiova - Seria Istorie, 22(1): 139-147.

[18] Nalivayko, N.V., Pushkareva, E.A. \& Shmatkov R.N. (2009). The quality of modern domestic education: the essence and problems: monograph. Novosibirsk: NSPU, pp. 312.

[19] Babich, V.V. (2013). On approaches to determining the forms of military (combat) actions - Bulletin of the Academy of military sciences, 3(44): 20-51.

[20] Navarro-Ibarra, L., García-Santillán, A. \& Molchanova V.S. (2020). Addiction Levels Toward the Internet: Empirical Evidence in College Students at Instituto Tecnológico De Sonora, México - European Journal of Contemporary Education, 9(2): 378-393. https://doi. org/10.13187/ejced.2020.2.378

[21] Pfanenshtil, I.A., Yatsenko, M.P. \& Borisenko I.G. (2013). Information technologies and their role in the sustainability of the Russian education system - Bulletin of the Irkutsk state technical University, 1(72): 274-279.

[22] Yin-Kim Yao, J. \& Ifenthaler, D. (2020). Reflections on Different Learning Analytics Indicators for Supporting Study Success. International Journal of Learning Analytics and Artificial Intelligence for Education, 2(2): 4-23. https://doi.org/10.3991/ijai.v2i2.15639

[23] Rossi Ramos, D. (2020). An Analysis of Subjectivation Processes Mediated by New Digital Technologies. International Journal of Emerging Technologies in Learning, 15(24): 1525. https://doi.org/10.3991/ijet.v15i24.19315

[24] Zhou, Z. \& Dong, B. (2021). Strategies and Implementation Paths for Curriculum Setting of Digital Media Major in the Digital Age. International Journal of Emerging Technologies in Learning, 16(15): 152-167. https://doi.org/10.3991/ijet.v16i15.24887

\section{$7 \quad$ Authors}

Dmitry V. Rakhinsky is a Professor, Associate Professor of the Department of Public Health at the V.F. Voino-Yasenetsky Krasnoyarsk State Medical University. He also works in Siberian Federal University and Krasnoyarsk State Agrarian University. His main scientific interests are globalistics and geopolitics, information technologies in education. Professional experience is more than 15 years.

Mikhail P. Yatsenko is a Professor, Associate Professor of the Department of Philosophy at the Siberian Federal University. His main scientific interests are philosophy of history, axiology, philosophy of education. His professional experience is more than 40 years.

Irina G. Sinkovskaya is an Associate Professor of Reshetnev Siberian State University of Science and Technology. She also works at the Siberian Federal University. She is interested in sociology of marriage and family, sociology of gender, social work with socially vulnerable groups. Her professional experience is more than 23 years.

Svetlana P. Shtumpf is a Professor, Associate Professor of the Department of Philosophy, Sociology and Religious Studies at the Krasnoyarsk State Pedagogical University named after V.P. Astafiev. Her main scientific interests are philosophy of history, axiology, philosophy of education. Her professional experience is more than 30 years.

Article submitted 2021-07-26. Resubmitted 2021-11-05. Final acceptance 2021-11-05. Final version published as submitted by the authors. 